\title{
Interaction of cyanide uptake by sorghum and wheat with nitrogen supply
}

\author{
S. Whankaew ${ }^{1}$, M. Machingura ${ }^{2}$, T. Rhanor ${ }^{2}$, K. Triwitayakorn ${ }^{1}$, and S. Ebbs ${ }^{2 *}$ \\ ${ }^{1}$ Institute of Molecular Biosciences, Mahidol University, Salaya, NakhonPathom 73170, Thailand. ${ }^{2}$ Department of Plant Biology \\ and Center for Ecology, Southern Illinois University, Carbondale, IL 62901-6509 USA. *Corresponding author: sebbs@plant. \\ siu.edu
}

\begin{abstract}
Cyanide occurs naturally in soils, arising from biological cyanogenesis and also in some cases from anthropogenic contamination. Plant utilization of cyanide at non-toxic concentrations as a supplemental source of nitrogen has been a topic of recent scientific interest and it was investigated here using sorghum (Sorghum bicolor L.) and wheat (Triticum aestivum L.). The accumulation of cyanogenic nitrogen in plant tissues was assessed under nitrogen regimes with specific combinations of cyanide, ammonium, and nitrate or each nitrogen source alone. Cyanogenic nitrogen accumulated in plant tissues when in combination with nitrate and accumulation of cyanogenic nitrogen decreased when ammonium was present. A greater increase of nitrogen in tissue from cyanide was observed in both species when cyanide was substituted for ammonium, but accumulation of cyanogenic nitrogen decreased when ammonium was present. A reciprocal nitrogen labeling experiment showed that nitrogen from nitrate and ammonium was accumulated preferentially over cyanogenic nitrogen. Differences in biomass and relative growth rate were observed in response to the treatments where plants were grown with nitrate, ammonium, or cyanide as the sole nitrogen source, but not when cyanide was present along with ammonium and nitrate. Physiological nitrogen use efficiency did not differ significantly within a species for any treatment imposed. The results suggest that cyanide as a nitrogen source can potentially support plant growth and development for up to eight weeks, but more effectively in combination with ammonium and nitrate.
\end{abstract}

Keywords: Ammonium, Cyanide, ß-Cyanoalanine pathway, nitrate, nitrogen 


\section{Introduction}

Nitrogen is an essential macronutrient required for proteins, photosynthesis, and a wide range of metabolic processes in plants. Nitrogen supply is also critical for biomass production, leaf area index, and relative growth rate of shoots (Radin 1983; Samuelson et al., 1995). The nitrogen used by plants that cannot engage in symbiotic nitrogen fixation is typically drawn from soil nitrate and ammonium (Harrison et al., 2007, 2008) but plants also opportunistically take up reduced organic forms of nitrogen in the soil (Nasholm et al., 2009). Cyanide is not generally thought of as a source of nitrogen for plants but rather as a poison and inhibitor. While cyanide at elevated concentrations inhibits metallo enzymes, including those associated with electron transport (Solomonson 1981) and nitrate assimilation (Barr et al., 1995), cyanide is naturally present in soils and in plant tissues at concentrations below those that cause adverse effects in plants. For example, cyanogenesis by soil bacteria and fungi introduces cyanide into rhizospheric soils of numerous plant species to concentrations as high as $100 \mathrm{mg} \mathrm{kg}$ $\mathrm{DW}^{-1}$ without apparent adverse effects (Owen and Zdor 2001). Cyanogenic glycosides are produced by $>2,000$ plant species as a defense against herbivores (Seigler 1991). The cyanide associated with these compounds is released into the plant tissues following insect grazing or into the soil environment as the cyanogenic plants decompose (e.g., Widmer and Abawi 2002). Plants in some terrestrial systems are therefore continuously exposed to some form of exogenous and/ or endogenous source of cyanide.

A variety of plant species take up cyanide from soil and hydroponic solutions (e.g., Ebbs et al., 2003; Ebbs et al., 2010; Larsen et al., 2004; Yu et al., 2004) and the results from some of these studies have suggested that the uptake of cyanide represents an opportunistic use of cyanogenic nitrogen as a replacement for or supplement of ammonium and nitrate. Similar results have been obtained from studies of ferricyanide and ferrocyanide uptake by plants (Ebbs et al., 2003; Samiotakis and Ebbs 2004; Yu et al., 2012). For the plant species tested and in response to nontoxic concentrations of cyanide typical of those that might be encountered in natural soils, such studies have consistently shown that when cyanide is present either in addition to both ammonium and nitrate, or when added in partial or complete replacement for ammonium, that tissue nitrogen concentration does not differ significantly from plants grown under the nominal nitrogen regimes. These observations have bolstered the contention that cyanide may be used by plants as an opportunistic source of nitrogen. Additional support for this contention has been obtained from studies demonstrating that the activity of enzymes associated with nitrogen assimilation (Yu and Zhang 2012) and the ß-cyanoalanine cyanide assimilatory pathway is altered in response to nontoxic concentrations of cyanogenic compounds (Machingura and Ebbs 2010), suggestive of a shift in nitrogen metabolism to allow the ammonium produced by the $\beta$-cyanoalanine pathway to augment or replace the exogenous ammonium supply. Collectively these studies indicate potential contributions of cyanide to plant nitrogen status. However, most of the associated experiments have been conducted over short periods of time, ranging from as little as $48 \mathrm{~h}$ (Ebbs et al., 2010; Yu et al., 2012; Yu and Zhang 2012) up to 7 d (e.g., Ebbs et al., 2010; Yu et al., 2008) so longer term impacts on biomass production have not been evaluated. Such studies have also not specifically examined if there is increased or decreased efficiency in biomass production resulting from the presence of cyanide as a possible source of nitrogen for plants.

The overarching goal of this research was to explore further the uptake of cyanide by plants and its possible contribution to plant growth and nitrogen status using wheat as a weakly cyanogenic (ostensibly acyanogenic) species and sorghum as a cyanogenic species. More specifically, the study here used longer term experiments than have been employed previously to examine the accumulation of cyanogenic nitrogen in the presence or absence of ammonium under constant 
nitrate supply. The preference for cyanide as a nitrogen source in comparison to ammonium and nitrate and under conditions was also examined by providing plants of these two species with only a single nitrogen source (cyanide, nitrate, or ammonium). Additionally, another objective of the present work was to determine the effect on the various treatment combinations of cyanide, ammonium, and nitrate on plant growth, biomass, and physiological nitrogen use efficiency (NUE). The NUE parameter was used here to evaluate the efficiency of biomass production as a function of the nitrogen source provided. The last objective of this work compared the data collected from the two species tested, sorghum (Sorghum bicolor L.) and wheat (Triticum aestivum L.), in an effort to determine if a naturally cyanogenic plant species (e.g., sorghum) responded differently to the imposed treatments than an acyanogenic plant species (e.g., wheat).

\section{Materials and Methods}

\subsection{Accumulation of cyanogenic nitrogen under variable ammonium and constant nitrate}

Seeds of sorghum (S. bicolor cv. GS201+) and wheat ( $T$ aestivum $\mathrm{cv}$. Wheaton) were germinated in autoclaved perlite: vermiculite $(1: 1 \mathrm{w} / \mathrm{w})$ wetted with sterile deionized water for one week under greenhouse conditions with ambient light and temperature conditions (light at 200-350 $\mu \mathrm{mol} \mathrm{m} \mathrm{m}^{-2} \mathrm{~s}^{-1}, 18-22{ }^{\circ} \mathrm{C}$, ambient relative humidity). Seedlings of each species of similar in size were transferred to pots containing 350-400 g of sterile perlite: vermiculite (one per pot for sorghum and two per pot for wheat).

After transplanting, watering was restricted to three times per week, once with $50 \mathrm{~mL}$ deionized water, once with $50 \mathrm{~mL}$ of nitrogen-free nutrient solution (6 mM KCl, $4 \mathrm{mM} \mathrm{CaCl}, 0.1 \mathrm{mM} \mathrm{KH_{2 }} \mathrm{PO}_{4}, 1 \mathrm{mM}$ $\mathrm{MgSO}_{4}, 12.5 \mu \mathrm{M} \mathrm{H}_{3} \mathrm{BO}_{3}, 1 \mu \mathrm{M} \mathrm{MnSO}_{4}, 1 \mu \mathrm{M} \mathrm{ZnSO}_{4}$, $0.5 \mu \mathrm{M} \mathrm{CuSO}_{4}, 0.1 \mu \mathrm{M} \mathrm{NiSO}_{4}, 0.1 \mu \mathrm{M} \mathrm{H}_{2} \mathrm{MoO}_{4}, 10$ $\mu \mathrm{M}$ Fe-HEDTA and $1 \mathrm{mM}$ MES, $\mathrm{pH}$ 6.0), and once with $50 \mathrm{~mL}$ of the nitrogen treatment solution. This nutrition solution was used in prior studies (Ebbs et al., 2003; Ebbs et al., 2010; Machingura and Ebbs 2010) and is modified from its original formulation (Johnson et al., 1957). The volumes were selected to insure that soil hydration was maintained, no leaching occurred, and all of the added solution was retained within the pot. The water application was used to maintain soil hydration while the nitrogen-free nutrient solution was added to insure the delivery of the necessary macroand micronutrients The nitrogen treatment solutions consisted of $10 \mathrm{mM} \mathrm{NO}_{3}^{-}\left(\mathrm{as}_{\mathrm{KNO}_{3}}\right.$ ) in combination with: 1) $0.1 \mathrm{mM} \mathrm{NH}_{4}^{+}$(as $\mathrm{NH}_{4} \mathrm{Cl}$ ); 2) $0.1 \mathrm{mM} \mathrm{CN}^{-}$(as $\mathrm{KCN}$ ); 3) $0.05 \mathrm{mM} \mathrm{NH}_{4}^{+}+0.05 \mathrm{mM} \mathrm{CN}^{-}$;) or 0.1 $\mathrm{mM} \mathrm{NH}_{4}^{+}+0.1 \mathrm{mM} \mathrm{CN}^{-}$. Cyanide was provided as the potassium salt (Cambridge Isotopes, Andover, MA, USA) and was added exclusively as $\mathrm{C}^{15} \mathrm{~N}$. Past experiments with hydroponically-grown wheat, sorghum, and willow (Salix eriocephala var. Michaux) plants have shown that cyanide concentrations up to $1.0 \mathrm{mM}$ cause no toxicity and the cyanogenic nitrogen atom is readily taken up and translocated by these species, with evidence of cyanide assimilation (Ebbs et al., 2003; Ebbs et al., 2010). The first three treatments were established to provide an equivalenttotal molar quantity of nitrogen with each treatment. The fourth treatment $\left(0.1 \mathrm{mM} \mathrm{NH}_{4}^{+}+0.1 \mathrm{mM} \mathrm{C}^{15} \mathrm{~N}^{-}\right)$provided surplus nitrogen at twice the molar quantity of nitrogen of the other three treatments. This experiment was carried outusing a randomized design with five replications per treatment. Following initiation of treatment, plant height was measured biweekly for eight weeks and used to calculate relative growth rate (RGR) for two-week growth intervals. Measurements of plant height were discontinued for wheat after the fourth week of treatment because all the plants began to flower so a full data set for RGR could not be derived for this species. To obtain a complete data set for RGR for both species the experiment was repeated with minor modifications. Plants were germinated as above in perlite-vermiculite for $7 \mathrm{~d}$ and then transferred into hydroponic solution with the same composition as the nitrogen-free nutrient solution indicated above. 
The same four treatments were imposed on the plants using non-labeled ammonium and cyanide with four replicates of each treatment. Plant height was measured immediately after transfer to hydroponics and weekly for eight weeks. The RGR was calculated for one week growth intervals.

After 8 weeks of treatment, tissues from the ${ }^{15} \mathrm{~N}$ labelling experiment were harvested, rinsed with deionized water, separated into roots and shoots, dried at 60 ${ }^{\circ} \mathrm{C}$, and ground to a fine powder to facilitate analysis. For stable isotope analysis, $\sim 5 \mathrm{mg}$ of labeled tissue was weighed into $8 \times 5 \mathrm{~mm}$ tin capsules (Elemental Microanalysis Ltd, Manchester, MA, USA). The samples were submitted to the Stable Isotope Facility at the University of California Davis for ${ }^{15} \mathrm{~N}$ analysis. The analysis provided the atom percentage for ${ }^{15} \mathrm{~N}$ and the total nitrogen concentration. The enrichment of ${ }^{15} \mathrm{~N}$ in the plant tissues was calculated relative to the control treatment (i.e., natural abundance of ${ }^{15} \mathrm{~N}$ in plant tissues) using standard techniques (Shearer and Kohl 1993). Tissue ${ }^{15} \mathrm{~N}$ concentrations were calculated using the total nitrogen concentration for each plant tissue and either the natural abundance of ${ }^{15} \mathrm{~N}(0.366 \%)$ or the ${ }^{15} \mathrm{~N}$ atom\% from the stable isotope analysis of the $\mathrm{C}^{15} \mathrm{~N}$ treated plants. The RGR data were analyzed using a two-way repeated measures ANOVA in SPSS (Windows v. 19.0) with species and treatment as main effects. Physiological nitrogen use efficiency (NUE) for shoot biomass was calculated for each treatment (Jiang et al., 2004) as the ratio of total plant biomass to total nitrogen in the plant biomass $\left(\mathrm{g} \mathrm{g}^{-1}\right)$. The results were analyzed using a two-way ANOVA with treatment and plant species as the main effects.

\subsection{Nitrate, ammonium, or cyanide as the single nitrogen source}

Sorghum and wheat seeds were germinated as described above, but after the germination period were transferred to a replete hydroponic solution with a formulation similar to that above but with $1.2 \mathrm{mM} \mathrm{KNO}_{3}, 0.8 \mathrm{mM}$ $\mathrm{Ca}\left(\mathrm{NO}_{3}\right)_{2}$ and $0.1 \mathrm{mM} \mathrm{NH}_{4} \mathrm{H}_{2} \mathrm{PO}_{4}$. Plants were grown in a growth chamber (Percival Scientific, Perry, IA) under a $16 \mathrm{~h}$ light regime at a light intensity of 350 $\mu \mathrm{Mol} \mathrm{m} \mathrm{m}^{-2} \mathrm{~s}^{-1}$ and ambient relative humidity. After one week of growth in this nutrient solution, the plants were transferred to pots containing $2 \mathrm{~L}$ of autoclaved $\mathrm{N}$ free nutrient solution described above and 0.2 millimoles of $\mathrm{KNO}_{3}, \mathrm{NH}_{4} \mathrm{Cl}$, or $\mathrm{KCN}$ was added to the nutrient solution to provide that single nitrogen source at a final concentration of $0.1 \mathrm{mM}$. Control plants were maintained in the same replete nutrient solution. Plants were grown under their $\mathrm{N}$ source regime for 8 weeks under the same growth chamber conditions, with fresh nutrient solution provided biweekly. For wheat, there were four replicates of each treatment. For sorghum there were four replicates for the cyanide treatment but only three replicates of the nitrate and ammonium treatments. The experiment utilized a fully randomized design. Plant height was again measured and RGR was determined for two week intervals as described above. After the eight weeks of growth, plants were harvested and separated into roots and shoots. Samples of each tissue ( $\sim 10 \mathrm{mg})$ were weighed into 10x12 mm tin capsules (CE Elantech, Lakewood, $\mathrm{NJ})$ and total nitrogen and carbon were determined using a FlashEA 1112 NC analyzer (Thermo Scientific Corp., Waltham, MA). The physiological NUE for biomass as described above was calculated for whole plant biomass to collectively account for both root and shoot production. The data were subjected to a oneway ANOVA with nitrogen source as the main effect.

\subsection{Preference for nitrate, ammonium, or cyanide as a N source}

Wheat and sorghum plants were germinated and grown in sterile sand under the greenhouse conditions described above for 10 and $23 \mathrm{~d}$, respectively. Plants were transplanted to the replete nutrient solution above under the same growth chamber conditions for one week. Plants of both species were transferred to either fresh replete nutrient solution or $\mathrm{N}$ free nutrient solution for four days to impose $\mathrm{N}$ starvation on half of the plants. Four wheat plants and three sorghum plants from each nitrogen regime were harvested and analyzed for total nitrogen as described below to verify 
that the nitrogen starvation treatment influenced plant nitrogen status. From the remaining plants of each species, single seedlings from the nitrogen replete or nitrogen starved pretreatment were transferred to 25 $\mathrm{mL}$ of fresh nutrient solution containing $1.0 \mathrm{mMKCN}$, $\mathrm{KNO}_{3}$, and $\mathrm{NH}_{4} \mathrm{Cl}$. To provide the three-way reciprocal labeling experiment, this treatment was set up with four replicates, differing only in which of these nitrogen sources was labeled with ${ }^{15} \mathrm{~N}$. One set of each of nitrogen replete and nitrogen starved plants of each species were placed in solutions with $\mathrm{KC}^{15} \mathrm{~N}, \mathrm{KNO}_{3}$, and $\mathrm{NH}_{4} \mathrm{Cl}$, one set in solutions with $\mathrm{KCN},{ }^{15} \mathrm{NO}_{3}$, and $\mathrm{NH}_{4} \mathrm{Cl}$, and a final set in solutions with $\mathrm{KCN}, \mathrm{NO}_{3}$, and ${ }^{15} \mathrm{NH}_{4} \mathrm{Cl}$. For each of these ${ }^{15} \mathrm{~N}$ treatment regimes, for each species and nitrogen pretreatment (replete or starved) there were four replicates, creating an experimental matrix with 48 total experimental units ( 2 species $\mathrm{x} 2$ nitrogen pretreatments $\mathrm{x} 4$ replicates $\mathrm{x}$ $3{ }^{15} \mathrm{~N}$ labeling regimes). Thus, each experimental unit consisted of $40 \mathrm{~mL}$ of treatment solution bearing one source ${ }^{15} \mathrm{~N}$ labeled of nitrogen, two unlabeled sources of nitrogen, and a single seedling of wheat or sorghum. The plants were exposed to this treatment regime under the growth chamber conditions for $72 \mathrm{~h}$. Plants were harvested and prepared for stable isotope analysis as described above. The results were subjected to a threeway ANOVA with nitrogen pretreatment, species, and treatment as the main effects. Where significant interactions were observed between main effects, the data were reanalyzed using the interaction means for those effects as a single treatment effect.

\section{Results}

\subsection{Accumulation of cyanogenic nitrogen under variable ammonium and constant nitrate}

There were no significant differences in shoot biomass between treatments or species (Table 1) nor were there any evident symptoms of deficiency or toxicity. Mean values for shoot biomass across the treatments ranged from 0.22 g DW for the treatment with ${ }^{15} \mathrm{~N}-1$ abeled cyanide to 0.32 g DW. Plants from the $0.1 \mathrm{mM} \mathrm{C}^{15} \mathrm{~N}^{-}$treatment had the greatest ${ }^{15} \mathrm{~N}$ concentration and the natural abundance concentration in the control plants was the lowest. There was no significant difference in ${ }^{15} \mathrm{~N}$ concentration between the two species. There was no difference in total shoot nitrogen within a species as a function of treatment, but there was a significant difference in total shoot nitrogen between species (Table 1). Collectively within a species across all treatments shoot nitrogen for wheat was $1.6 \%$ as compared to $1.1 \%$ for sorghum. For physiological NUE, there was no difference within a species between treatments (Table 1). Collectively for physiological NUE for all treatments within a species, the value for sorghum $(\mathrm{NUE}=97.8)$ was significantly higher than for wheat $(\mathrm{NUE}=67.8)$.

The patterns for RGR differed for each species over the course of the experiment (Figure 1A-1B). The RGR for sorghum showed no significant difference across the four growth intervals, although the mean values for the first two intervals were greater than for the second two intervals. For wheat, RGR increased significantly between the first and second growth intervals. There was no significant difference in RGR in response to treatment for either species. The RGR data obtained when the experiment was repeated (Figure 1C-1D) produced similar results in that there were no persistent differences in RGR between treatments within a species. There were one or two growth intervals during the middle of the experiment where some significant differences were evident for sorghum (e.g, after 4-5 weeks of growth, Figure 1C) for the treatments which included $0.1 \mathrm{mM}$ cyanide, but the RGR values were not significantly different between treatments within a species before or after those particular intervals. The values obtained for ${ }^{15} \mathrm{~N}$ enrichment indicated that cyanogenic nitrogen was transported into plant shoots (Figure 2). Enrichment values were $>1,000$ for both species and treatments, and significant differences in enrichment were observed between treatments and between species but there was no interaction between these two main effects. Plants treated with $0.1 \mathrm{mM} \mathrm{C}^{15} \mathrm{~N}$ alone showed a ${ }^{15} \mathrm{~N}$ enrichment significantly greater than the $0.05 \mathrm{mM} \mathrm{NH}_{4}^{+}+0.05 \mathrm{mM} \mathrm{C}^{15} \mathrm{~N}^{-}$treatment but 
not for $0.1 \mathrm{mM} \mathrm{NH}_{4}^{+}+0.1 \mathrm{mM} \mathrm{C} 15 \mathrm{~N}^{-}$treatment (Figure 2A). The ${ }^{15} \mathrm{~N}$ enrichment was significantly less for wheat as compared to that observed for sorghum (Figure 2B).
A similar pattern was observed within a species across treatments for the calculated ${ }^{15} \mathrm{~N}$ concentration in the shoots (Figure 2C-2D).

Table 1. Biomass, total nitrogen concentration, and physiological nitrogen use efficiency (NUE) for shoots of sorghum and wheat at harvest following eight weeks of irrigation with nutrient solution containing $10 \mathrm{mM}$ nitrate and one of four $\mathrm{CN}^{-}$and/or $\mathrm{NH}_{4}^{+}$treatments. Data represent the mean and standard error of the mean respectively $(n=5)$.

\begin{tabular}{lcccc} 
& \multicolumn{4}{c}{ TREATMENT $^{\mathbf{a}}$} \\
\cline { 2 - 5 } Species & $\mathrm{T} 1$ & $\mathrm{~T} 2$ & $\mathrm{~T} 3$ & $\mathrm{~T} 4$ \\
\cline { 2 - 5 } Sorghum & \multicolumn{4}{c}{ Biomass, $g$ DW } \\
\cline { 2 - 5 } Wheat & $0.27 \pm 0.03$ & $0.22 \pm 0.04$ & $0.30 \pm 0.04$ & $0.27 \pm 0.01$ \\
& $0.28 \pm 0.04$ & $0.28 \pm 0.02$ & $0.32 \pm 0.03$ & $0.27 \pm 0.04$ \\
\cline { 2 - 5 } Sorghum & \multicolumn{5}{c}{ Total N, \% } \\
\cline { 2 - 5 } Wheat & $1.0 \pm 0.1$ & $1.2 \pm 0.1$ & $1.1 \pm 0.1$ \\
& $1.5 \pm 0.1$ & $1.8 \pm 0.2$ & $1.4 \pm 0.2$ \\
\cline { 2 - 5 } Sorghum & \multicolumn{4}{c}{ Physiological NUE, $g g^{-1}$} \\
Wheat & $107.7 \pm 8.6$ & $96.4 \pm 10.0$ & $83.4 \pm 6.0$ \\
\hline
\end{tabular}

a: $\mathrm{T} 1=0.1 \mathrm{mM} \mathrm{NH}_{4}^{+}$(control treatment with natural abundance $\left.{ }^{15} \mathrm{~N}\right) ; \mathrm{T} 2=0.1 \mathrm{mM} \mathrm{C}^{15} \mathrm{~N}^{-} ; \mathrm{T} 3=0.05 \mathrm{mM} \mathrm{NH}_{4}^{+}+0.05 \mathrm{mM} \mathrm{C}^{15} \mathrm{~N}^{-}$; $\mathrm{T} 4=0.1 \mathrm{mM} \mathrm{NH}_{4}^{+}+0.1 \mathrm{mM} \mathrm{C}^{15} \mathrm{~N}^{-}$

\subsection{Nitrate, ammonium, or cyanide as the single} nitrogen source

Although nitrate, ammonium, and cyanide were supplied in the single source treatments at equivalent rates during this experiment, significant differences in some biomass values were evident between and within species (Figure 3A). There was no significant difference in sorghum shoot or root biomass across treatments. In contrast, for wheat roots biomass was reduced significantly in single nitrogen treated plants in comparison to control plants. Shoot biomass was reduced significantly only in the nitrate only and cyanide only treatments relative to control.
Between species, wheat roots and/or shoots in some treatments (e.g., control and ammonium only treatments) had significantly greater biomass in comparison to the corresponding tissues for sorghum. Within a species, treatment with either nitrate or ammonium as the single nitrogen source resulted in a significant decrease in the root: shoot ratio compared to the nitrogen replete hydroponic solution control plants. There was no significant difference in root: shoot ratio within a species between the nitrogen replete control plants and the plants that received cyanide as the only nitrogen source, but variability was high for cyanide-treated plants as indicated from the error term (Figure 3B). 


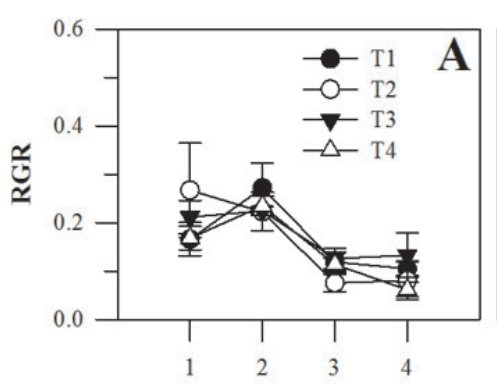

Growth interval

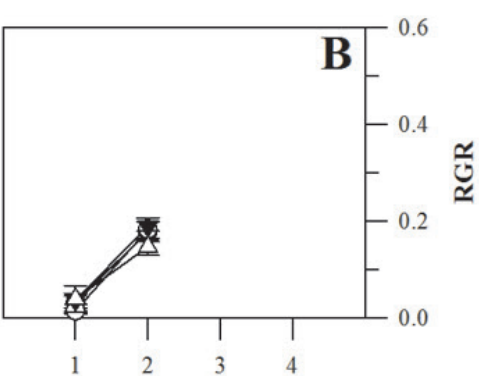

Growth interval



Growth interval

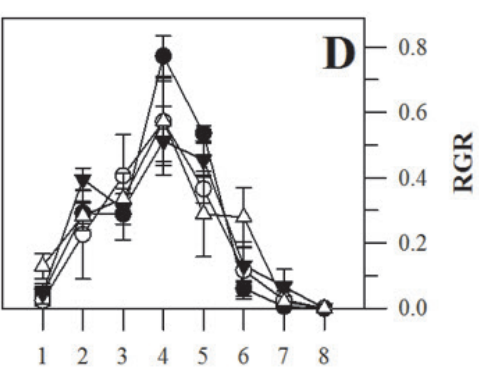

Growth interval

Figure 1. Relative growth rate $(\mathrm{RGR})$ for shoots of sorghum $(\mathbf{A}, \mathbf{C})$ and wheat $(\mathbf{B}, \mathbf{D})$ in response to treatment with $10 \mathrm{mM}$ nitrate and one of four $\mathrm{CN}^{-}$and/or $\mathrm{NH}_{4}^{+}$treatments: $\mathrm{T} 1=0.1 \mathrm{mM} \mathrm{NH}_{4}^{+}$(control treatment with natural abundance $\left.{ }^{15} \mathrm{~N}\right) ; \mathrm{T} 2=0.1 \mathrm{mM} \mathrm{C}^{15} \mathrm{~N}^{-} ; \mathrm{T} 3=0.05 \mathrm{mM} \mathrm{NH}_{4}^{+}+0.05 \mathrm{mM} \mathrm{C}^{15} \mathrm{~N}^{-} ; \mathrm{T} 4=0.1 \mathrm{mM} \mathrm{NH} 4^{+}+0.1 \mathrm{mM} \mathrm{C}^{15} \mathrm{~N}^{-}$. Plants were grown either in sterile potting mix $(\mathbf{A}, \mathbf{B})$ or nitrogen free nutrient solution $(\mathbf{C}, \mathbf{D})$. The RGR was calculated on either a biweekly $(\mathbf{A}, \mathbf{B})$ or weekly $(\mathbf{C}, \mathbf{D})$ basis. Data represent the mean and standard error $(\mathrm{n}=4-5)$. Within a panel, means with different letters (a-c for sorghum, $\mathrm{x}-\mathrm{z}$ for wheat) are significantly different from each other $(a=0.05)$.

The mean values obtained for the cyanide treatment for each species were comparable to the corresponding means from the nitrate or ammonium treatments. There were some differences in RGR for the first two growth intervals but there was no difference evident within a species between treatments for the latter two growth intervals (Figure 4). Modest effects of treatment on total plant nitrogen, carbon, and/or C:N ratio were observed across treatments and species
(Figure 5. Shoot nitrogen differed significantly as a function of treatment only for wheat, with control wheat plants showing greater nitrogen content that the shoots of wheat plants receiving only a single nitrogen source (Figure 5A). Shoot nitrogen values were similar for both sorghum and wheat. There were significant differences in root nitrogen within a species as a function of treatment but there was no difference between species. 

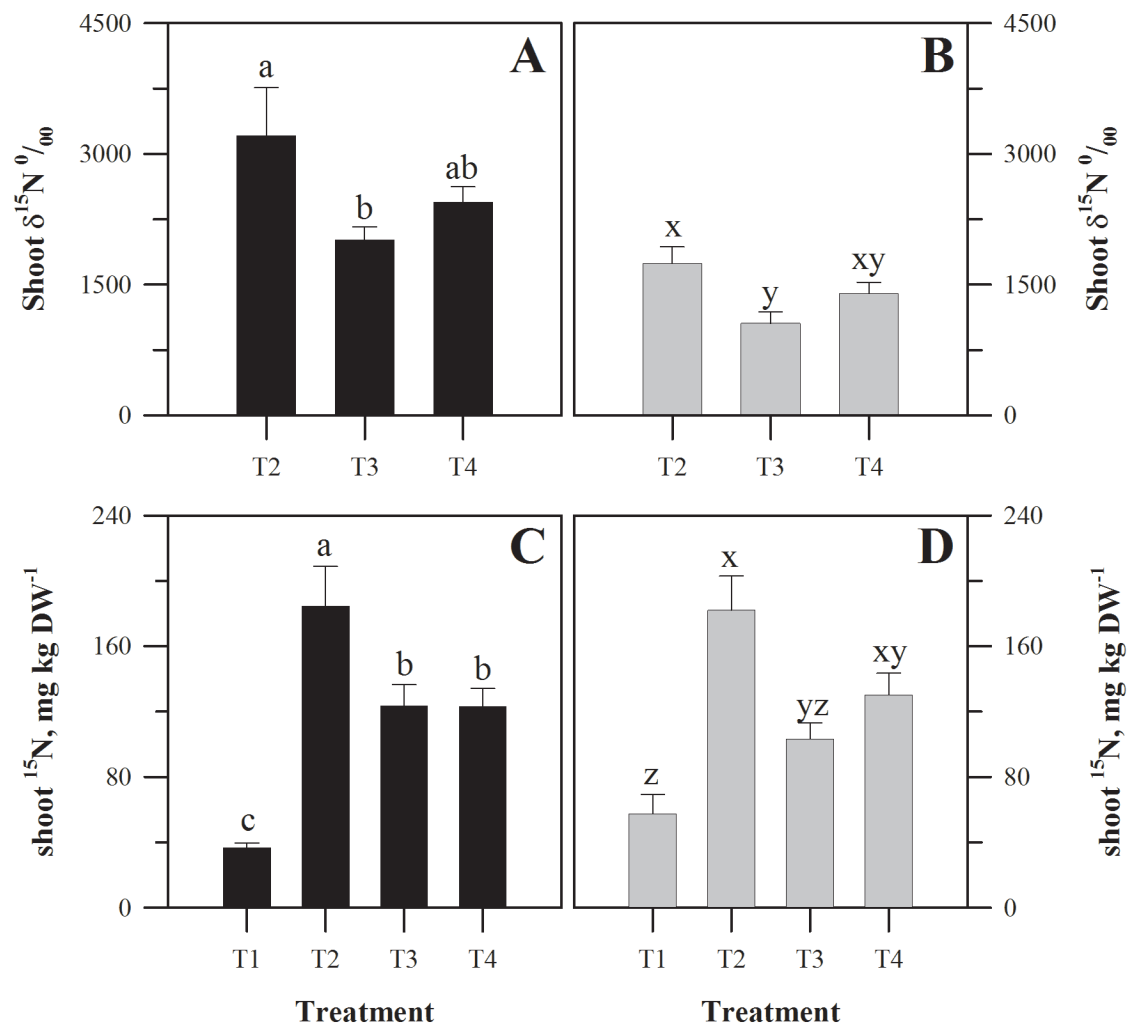

Figure 2. The ${ }^{15} \mathrm{~N}$ enrichment $(\mathbf{A}, \mathbf{B})$ and ${ }^{15} \mathrm{~N}$ concentration $(\mathbf{C}, \mathbf{D})$ in shoots of sorghum $(\mathbf{A}, \mathbf{C})$ and wheat $(\mathbf{B}, \mathbf{D})$ grown in sterile potting mix and treated with $10 \mathrm{mM}$ nitrate and one of four $\mathrm{CN}^{-}$and/or $\mathrm{NH}_{4}^{+}$treatments (see legend of Table 1 or Figure 1 for treatment codes). Data represent the mean and standard error $(n=5)$. Within a panel, means with different letters are significantly different from each other $(a=0.05)$.

For both species, the plants provided with nitrate as the sole nitrogen source had the greatest root nitrogen content. For wheat, the cyanide treated plants had the lowest root nitrogen content, although this value was not significantly different from the control and ammonium treatments. For wheat, the control plants had the smallest root nitrogen content. The only significant difference observed for shoot carbon was for shoots of wheat (Figure 5B). Cyanide-treated plants of wheat and sorghum had significantly higher shoot carbon $(40.9 \%)$ and nitrate-treated the lowest (37.7\%). In terms of the resulting C: $\mathrm{N}$ ratios, the pattern for roots as a function of treatment and species (Figure 5C) was for each species inverted relative to the corresponding results for root nitrogen content. Since the sorghum plants provided with cyanide as the sole nitrogen source had the lowest tissue nitrogen content, the same treatment for this species resulted 
in the greatest $\mathrm{C}: \mathrm{N}$ ratio for both shoots and roots. Similarly, since the nitrate treated wheat plants had the greatest root nitrogen content, the $\mathrm{C}: \mathrm{N}$ ratio for wheat roots was significantly less than that for the control and cyanide treatments. In terms of physiological NUE for biomass, there was no difference across treatments or between species (Figure 5D). The mean value for sorghum plants treated with cyanide as the sole nitrogen source was higher than the other three treatments, but there was more variability in the results.
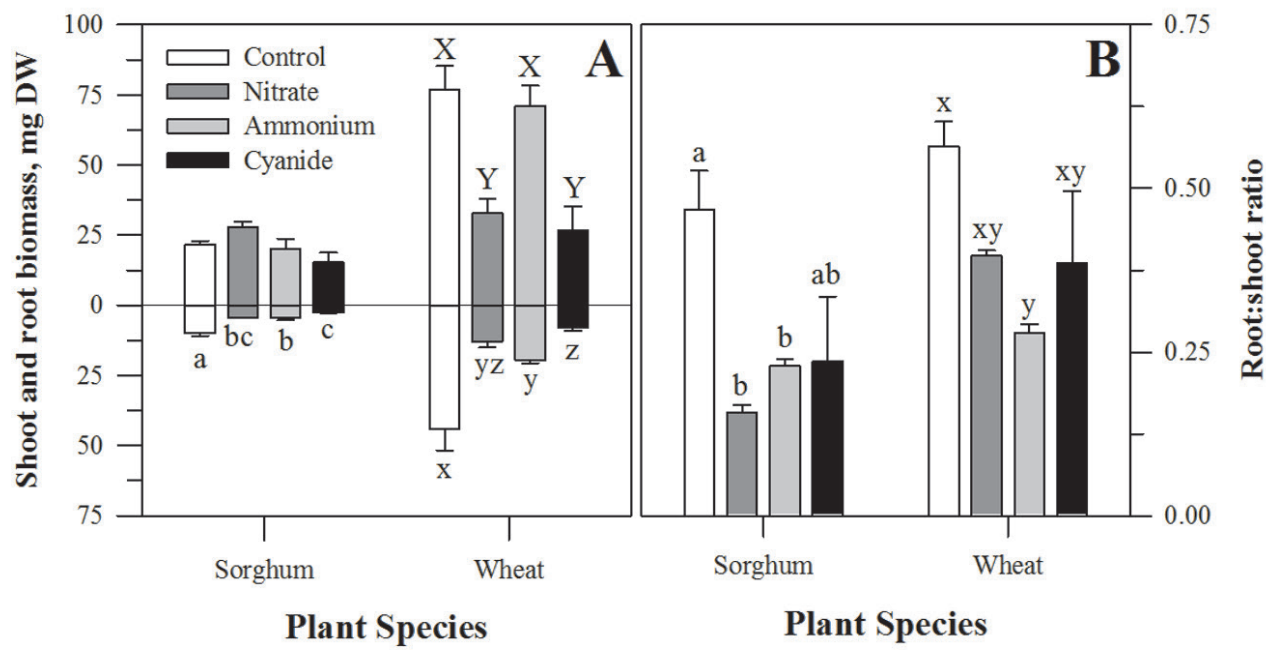

Figure 3. Root biomass, shoot biomass (A), and root:shoot biomass ratio (B) of sorghum and wheat plants grown hydroponically for eight weeks in nitrogen-replete nutrient solution (control) or a nitrogen free nutrient solution containing $0.1 \mathrm{mM}$ of nitrate, ammonium, or cyanide as the sole nitrogen source. Data represent the mean and standard error $(n=3-4)$. Within a species (a-c for sorghum, $\mathrm{x}-\mathrm{z}$ for wheat), means with different letters are significantly different from each other $(a=0.05)$. For the biomass data, capital letters are used for shoots (upper panel) when significant differences occurred across treatments within a species while lower case letters are used similarly for roots (lower panel). 


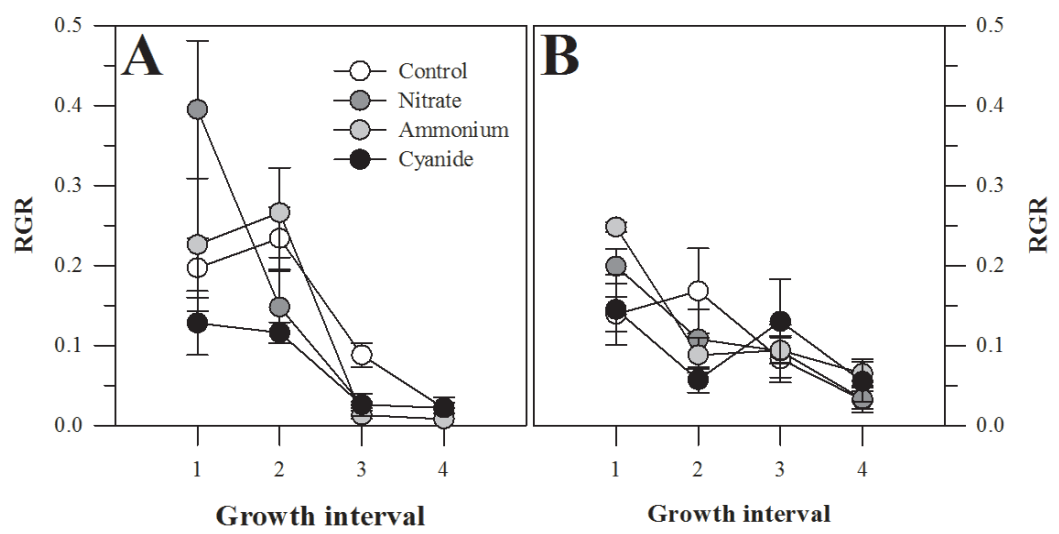

Figure 4. Relative growth rate (RGR) for shoots of sorghum (A) and wheat (B) plants grown hydroponically for eight weeks in nitrogen replete nutrient solution (control) or a nitrogen free nutrient solution containing $0.1 \mathrm{mM}$ of either nitrate, ammonium, or cyanide as the sole nitrogen source. The RGR was calculated biweekly. Data represent the mean and standard error $(n=3-4)$.

\subsection{Preference for nitrate, ammonium, or cyanide as a nitrogen source}

For the plants used in the three-way reciprocal isotope labeling experiment, the starvation period imposed on half the plants of each species resulted in a significant decrease in root and shoot nitrogen concentration as compared to the same tissues from plants grown under nitrogen replete conditions (Figure 6). The reduction in nitrogen concentration for wheat was $\sim 30 \%$ and closer to $50 \%$ for sorghum. However, when the data for the reciprocal labeling experiment were examined, there was no statistically significant difference between the nitrogen replete and nitrogen starved plants within any of the treatments so the data for that treatment were combined, reducing the main effects to species and ${ }^{15} \mathrm{~N}$ source. The pooling of the data in this manner facilitated the observation that there was no significant difference in root or shoot biomass was no significant difference in root or shoot biomass within a species as a function of either nitrogen pretreatment or form of ${ }^{15} \mathrm{~N}$ applied (Figure 7A). For each species within the roots and within the shoots, there was a significant effect of ${ }^{15} \mathrm{~N}$ source on tissue ${ }^{15} \mathrm{~N}$ concentration (Figure 7B), indicating an apparent preference for or prioritization of the nitrogen sources. For shoots, the ${ }^{15} \mathrm{~N}$ concentration demonstrated that the supplied nitrate nitrogen was the principal source for foliar nitrogen, followed by ammonium and then cyanide. Roots of sorghum showed the greatest increase in ${ }^{15} \mathrm{~N}$ concentration from ammonium while the increase from cyanide or nitrate was similar. Wheat, in contrast, showed the greatest increase from nitrate with a similar, smaller increase from cyanide and ammonium (Figure 7). 


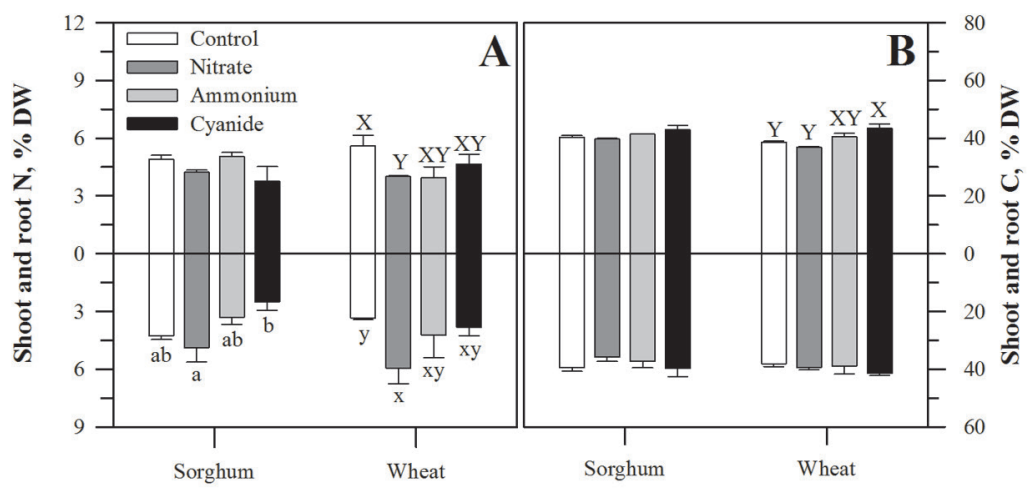

Plant Species

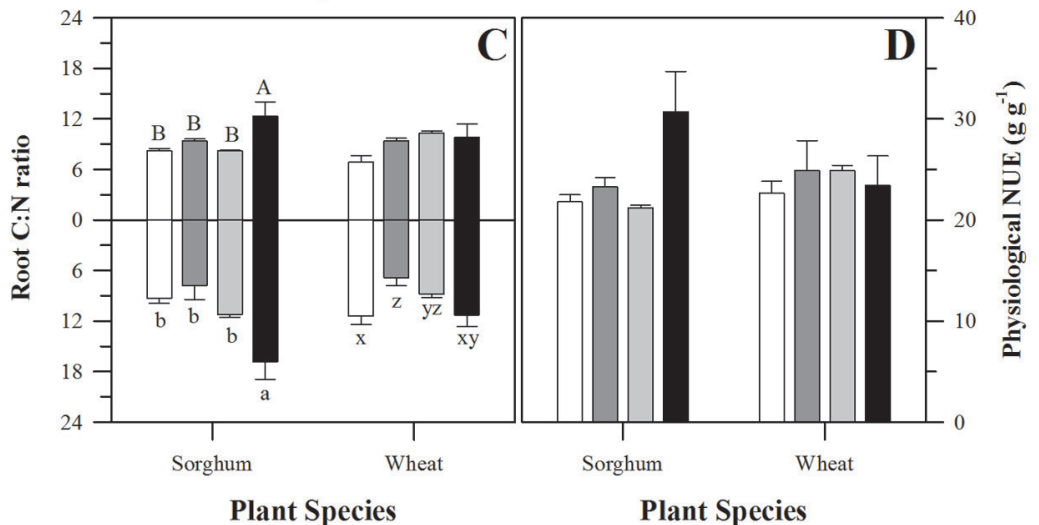

Figure 5. Tissue nitrogen (B), tissue carbon (B), tissue C:N ratio (C), and physiological nitrogen use efficiency (NUE) on a whole plant basis (D) for sorghum and wheat plants grown hydroponically for eight weeks in nitrogen replete nutrient solution (control) or a nitrogen free nutrient solution containing $0.1 \mathrm{mM}$ of either nitrate, ammonium, or cyanide as the sole nitrogen source. Data represent the mean and standard error $(n=3-4)$. Within a species (a-c for sorghum, $x-z$ for wheat), means with different letters are significantly different from each other $(a=0.05)$. For shoot (upper panel) and root (lower panel) data, capital letters are used for shoots when significant differences occurred across treatments within a species while lower case letters are used similarly for roots. 


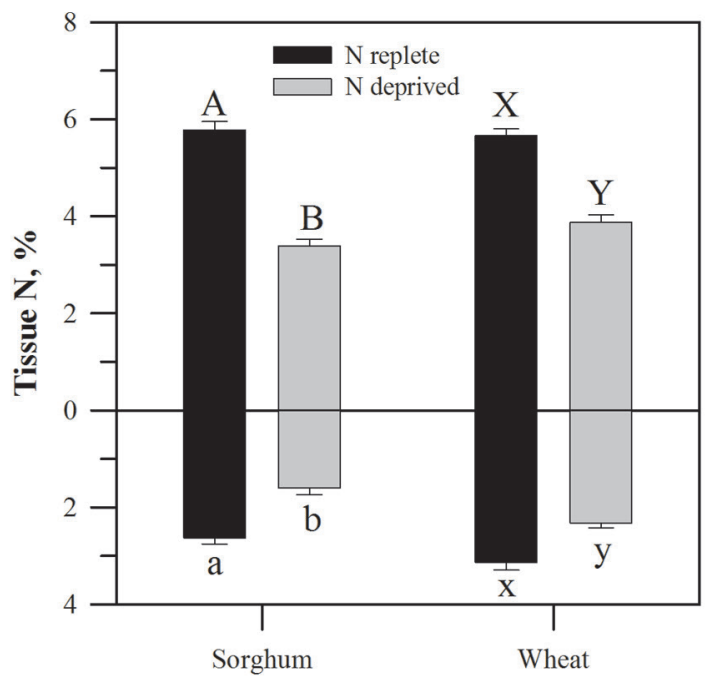

Species

Figure 6. Total nitrogen in roots (lower panel) and shoots (upper panel) of sorghum and wheat grown hydroponically in nitrogen-replete or a nitrogen-free nutrient solution for four days.Data represent the mean and standard error $(n=3$ 4). Within a species (a-c for sorghum, $\mathrm{x}-\mathrm{z}$ for wheat), means with different letters are significantly different from each other $(\mathrm{a}=0.05)$. For shoot (upper panel) and root (lower panel) data, capital letters are used for shoots when significant differences occurred across treatments within a species while lower case letters are used similarly for roots.

\section{Discussion}

In soils there is competition in the rhizosphere between plants and other organisms for available nitrogen. Plants can cope with supply limitations and competition by opportunistically utilizing other forms of nitrogenin the rhizosphere (e.g., amino acids) to replace or supplement soil nitrate and ammonium (Nasholm et al., 2009). One question of interest is whether cyanogenic compounds in the rhizosphere might be perceived by plants as opportunistic forms of nitrogen when present at nontoxic concentrations. A specific positive contribution of the uptake of exogenous, rhizospheric cyanide for plant growth and/or nitrogen status has not been clearly demonstrated but has been suggested by short term studies (Ebbs et al., 2003; Ebbs et al., 2010;
Larsen et al., 2004; Larsen et al., 2005; Machingura and Ebbs 2010; Yu et al., 2008; Yu et al., 2012; Yu et al., 2004). The overall goal of the research here was to conduct longer term studies to provide additional information on the possible contribution of cyanide to plant growth and nitrogen status.

When the accumulation of cyanogenic nitrogen under different combinations of cyanide and ammonium under constant nitrate supply was examined, there was increased enrichment of cyanogenic nitrogen in plant shoots when ammonium was absent and decreased accumulation of cyanogen nitrogen when ammonium was present. This trend is similar to what was observed in wheat roots and shoots in a short term two-way reciprocal labeling study with ${ }^{15} \mathrm{~N}^{-}$cyanide and ${ }^{15} \mathrm{~N}^{-}$ammonium (Ebbs et al., 2010), and studies 


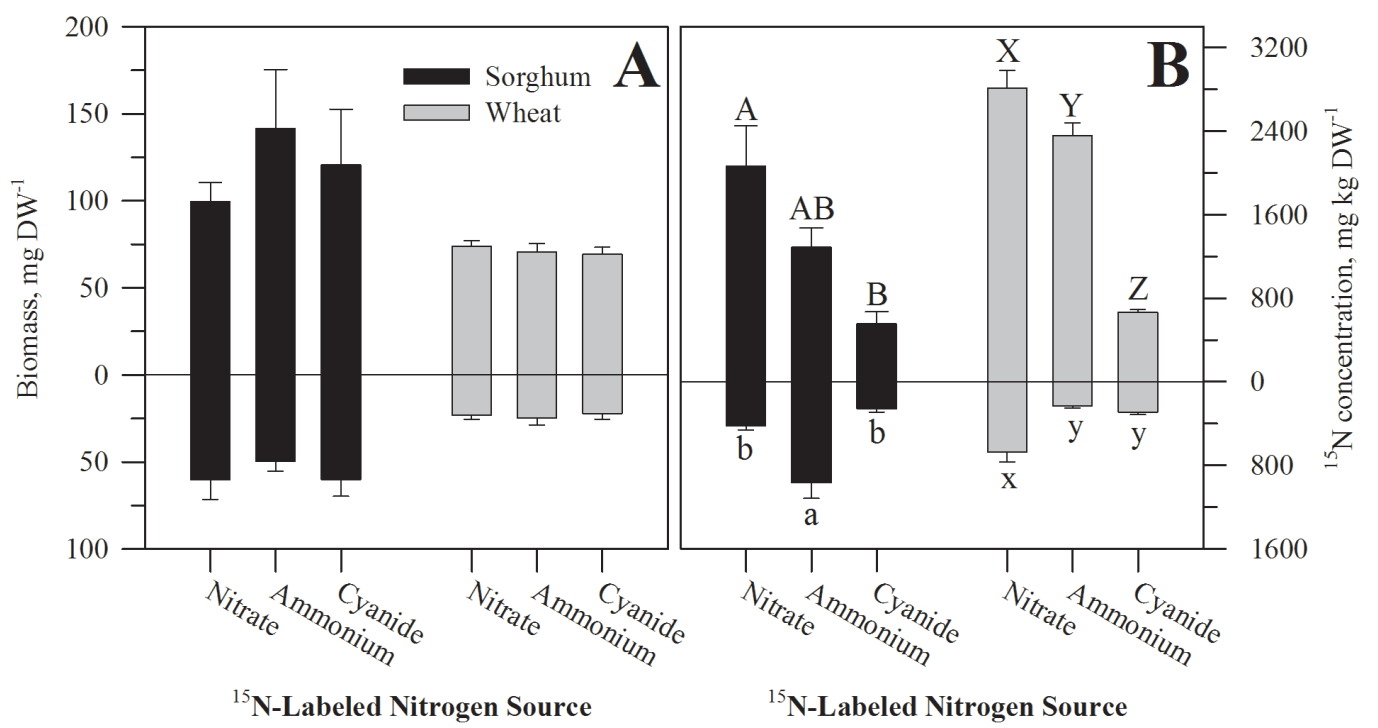

Figure 7. Biomass (A) and ${ }^{15} \mathrm{~N}$ concentration (B) in roots (lower panels) and shoots (upper panels) of sorghum and wheat grown hydroponically for four days in nutrient solution containing $1.0 \mathrm{mM}$ of cyanide, ammonium, and nitrate. The experiment was performed as a three-way reciprocal ${ }^{15} \mathrm{~N}$-isotope labeling experiment in which one of the three nitrogen compounds was labeled with ${ }^{15} \mathrm{~N}\left(\mathrm{C}^{15} \mathrm{~N},{ }^{15} \mathrm{NH}_{4}\right.$, or $\left.{ }^{15} \mathrm{NO}_{3}\right)$ and the other two carried no isotopic label. Data represent the mean and standard error $(n=4)$ for plants receiving the treatment with the indicated labeled nitrogen source. Within a species, means with different letters are significantly different from each other (a-c for sorghum, $\mathrm{x}-\mathrm{z}$ for wheat, $\mathrm{a}=0.05$ ). For shoot and $\operatorname{root}^{15} \mathrm{~N}$ data $(\mathbf{B})$, capital letters are used for shoots when significant differences occurred across treatments within a species while lower case letters are used similarly for roots.

ferrocyanide or ferricyanide as sources of cyanogenic nitrogen (Ebbs et al., 2003; Larsen et al., 2005; Yu et al., 2008; Yu et al., 2012). Two studies with weeping willow (Salix babylonica L.) and one with rice (Oryza sativa $\mathrm{L}$.) demonstrated that when plants were deprived of nitrogen, the accumulation and assimilation of cyanide from ferrocyanide and ferricyanide increased (Yu et al., 2008; Yu et al., 2012). Such results imply that potential interactions between cyanide and ammonium with respect to plant nitrogen status can occur at least as long as theduration of the experiments here.

The nature of this putative interaction between cyanide and ammonium may not be a direct transport interaction
(Ebbs et al., 2010) but indirect interactions might be possible. One explanation for this interaction involves the $\beta$-cyanoalanine pathway, the principal cyanide assimilation pathway in plants. In the pathway, cyanide is metabolized to produce asparagine, aspartate, and ammonium. Asparaginase can subsequently promote the release of an amide group from asparagine which also contributes to the ammonium pool. Since assimilation of cyanide via the $\beta$-cyanoalanine pathway leads to the formation of ammonium (Piotrowski et al., 2001), the interplay between cyanide and ammonium may involve cyanide assimilated by the $\beta$-cyanoalanine pathway providing an alternative source of ammonium (Machingura and Ebbs 2010). Cyanide is also known 
to regulate the activity of nitrate reductase (Barr et al., 1995) and recent evidence with rice has shown that the combination of nitrate and cyanide as the nitrogen source resulted in lower rates of nitrate reductase activity and slower growth as compared to plants provided nitrogen as ammonium and cyanide ( $\mathrm{Yu}$ and Zhang 2012). A logical result of impaired assimilation of nitrate in the presence of cyanide in the substrate might be enhanced uptake and assimilation of cyanide to provide ammonium to offset a decrease in nitrate reduction. This conclusion is substantiated by the observation in all three experiments performed here in that plants treated with nitrogen regimes which included cyanide, as well as cyanide as the sole nitrogen source, had total tissue nitrogen concentrations that were not significantly different from control plants. The threeway reciprocal ${ }^{15} \mathrm{~N}$ labelling illustrated though that sorghum and wheat displayed a greater accumulation of ammonium or nitrate over cyanide when all three forms of nitrogen are present, which may indicate a greater preference or prioritization of these chemical forms of nitrogen over cyanide.

Physiological NUE can be an expression of the nitrogen use efficiency for plant productivity (e.g., Eckstein and Karlsson 2001; Ingestad 1979) or a parameter used to quantify the efficacy of nitrogen fertilizer strategies for plant biomass or seed yield (e.g., Duan et al., 2007; Jiang et al., 2004). Some studies with rice and maize (Zea mays L.) have shown that biomass and production and physiological NUE values are maintained across different fertilizer regimes with different ratios of ammonium and nitrate (Duan et al., 2007; Jiang et al., 2004). In each experiment here where cyanide was included with nitrate and ammonium, the physiological NUE values did not differ within a plant species between treatments or in comparison to control plants of that species. Since total biomass and RGR also did not differ significantly either within a species in response to these treatments, such results indicate that cyanogenic nitrogen did not alter the efficiency of nitrogen utilization. Results from other studies in which plants have been exposed to single nitrogen sources (e.g., nitrate, ammonium, or individual amino acids) have shown that the resulting plant growth depends on several factors, including the form of nitrogen, the total concentration of nitrogen applied, and the plant species (Cambui et al., 2011; Carlisle et al., 2012; Samuelson et al., 1995). The results here from both sorghum and wheat may indicate a comparable limitation to biomass production resulting from cyanide as the sole nitrogen source.

There is conflicting information on differential cyanide transport or assimilation by cyanogenic and acyanogenic plants, but current evidence suggests that cyanogenic plants do not necessarily have an inherently enhanced capacity to assimilate cyanide via the $\beta$-cyanoalanine pathway because the magnitude of the differences in rates of enzyme activity depends upon the specific tissue sampled and the stage of development of those tissues (Larsen et al., 2004; Wurtele et al., 1984; Yu et al., 2004). Some differences between sorghum and wheat were observed in this study and in a prior study (Ebbs et al., 2010). In experiments within this study, sorghum plants showed significantly higher values for physiological NUE than wheat only when nitrate was present and not when cyanide was the only nitrogen source. As the sorghum plants in some experiments here had lower biomass, RGR, and/or lower tissue nitrogen concentrations as compared to the wheat plants, inherent differences between the two species here may have obscured metabolic differences in the capacity of each species to utilize cyanide as a source of nitrogen for growth and development. Consequently, there is insufficient data on which to base a definitive conclusion other than to suggest that sorghum as a cyanogenic species was not necessarily more effective than an acyanogenic species such as wheat in the utilization of cyanide to support plant growth and NUE.

In conclusion, the results here suggest that cyanogenic nitrogen in the rhizosphere may represent a short-term source of nitrogen under conditions where ammonium may be limiting. The species tested seem to have the capacity to utilize cyanide to augment nitrogen metabolism can occur for discrete periods of time 
(e.g., over the time frames utilized in the experiments here), but perhaps not as effectively alone in terms of growth RGR or biomass production as when cyanide is present in combination with other nitrogen sources. Results from rice (Yu et al., 2012; Yu and Zhang 2012) and prior studies with sorghum and wheat (Ebbs et al., 2010; Machingura and Ebbs 2010) suggest a complex interaction between the nitrogen forms supplied and activity of enzymes associated with primary nitrogen metabolism that warrant further investigation. The implications of interactions between ammonium, nitrate, and cyanide may have relevance for plant growth, development, reproduction and yield. Such interactions may be particularly relevant in agricultural and natural systems where cyanide is present.

\section{Acknowledgments}

Support for this research was provided to S.W. and K.T. from the Thailand Research Fund through the Royal Golden Jubilee Ph.D program (Grant No. Ph.D 4LMU/51/W1) and to S.E. through a Southern Illinois University Faculty SEED Grant.

\section{References}

Barr, R., Boettger, M., Crane, F.L., Morre, D.J. 1995. Nitrate reductase activity of plasma membranes from cultured carrot cells. Protoplasma. 184, 151-157.

Cambui, C.A., Svennerstam, H., Gruffman, L., Nordin, A., Ganeteg, U., Näsholm, T. 2011. Patterns of plant biomass partitioning depend on nitrogen source. PLoS ONE. 6,

Carlisle, E., Myers, S.S., Raboy, V., Bloom, A.J. 2012. The effects of inorganic nitrogen form and $\mathrm{CO}_{2}$ concentration on wheat yield and nutrient accumulation and distribution. Front. Plant Sci. 3, 195.
Duan, Y.H., Zhang, Y.L., Ye, L.T., Fan, X.R., Xu, G.H., Shen, Q.R. 2007. Responses of rice cultivars with different nitrogen use efficiency to partial nitrate nutrition. Annal Bot. 99, 1153-1160.

Ebbs, S.D., Bushey, J., Poston, S., Kosma, D. Samiotakis, M., Dzombak, D. 2003. Transport and metabolism of free cyanide and iron cyanide complexes by willow. Plant Cell Environ. 26, 1467-1478.

Ebbs, S.D., Kosma, D.K., Nielson, E.H., Machingura, M., Baker, A.J.M., Woodrow, I.E. 2010. Nitrogen supply and cyanide concentration influence the enrichment of nitrogen from cyanide in wheat (Triticum aestivum L.) and sorghum (Sorghum bicolor L.). Plant Cell Environ. 33, 1152-1160.

Eckstein, R.L., Karlsson, P.S. 2001. Variation in nitrogen-use efficiency among and within subarctic graminoids and herbs. New Phytol. 150, 641-651.

Harrison, K.A., Bol, R., Bardgett, R.D. 2007 Preferences for different nitrogen forms by coexisting plant species and soil microbes. Ecology. 88, 989-999.

Harrison, K.A., Bol, R., Bardgett, R.D. 2008. Do plant species with different growth strategies vary in their ability to compete with soil microbes for chemical forms of nitrogen?. Soil Biol. Biochem. 40, 228-237.

Ingestad, T. 1979. Nitrogen stress in birch seedlings. Physiol. Plant. 45, 149-157.

Jiang, L., Dai, T., Jiang, D., Cao, W., Gan, X., Wei, S. 2004. Characterizing physiological N-use efficiency as influenced by nitrogen management in three rice cultivars. Field Crop Res. 88, 239250 .

Johnson, C.M., Stout, P.R., Broyer, T.C., Carlton, A.B. 1957. Comparative chlorine requirements of different plant species. Plant Soil. 8, 337-353. 
Larsen, M., Trapp, S., Pirandello, A. 2004. Removal of cyanide by woody plants. Chemosphere. 54 , 325-333.

Larsen, M., Ucisik, A., Trapp, S. 2005. Uptake, metabolism, accumulation, and toxicity of cyanide in willow trees. Environ. Sci. Technol. 39, 2135-2142.

Machingura, M., Ebbs, S. 2010. Increased b-cyanoalanine synthase and asparaginase activity in nitrogen-deprived wheat exposed to cyanide. J. Plant Nutr. Soil Sci. 173, 808-810.

Nasholm, T., Kielland, K., Ganeteg, U. 2009. Uptake of organic nitrogen by plants. New Phytol. 182, 31-48.

Owen, A., Zdor, R. 2001. Effect of cyanogenic rhizobacteria on the growth of velvetleaf (Abutilon theophrasti) and corn (Zea mays) in autoclaved soil and the influence of supplemental glycine. Soil Biol. Biochem. 33, 801-809.

Piotrowski, M., Schonfelder, S., Weiler, E.W. 2001. The Arabidopsis thaliana isogene NIT4 and its orthologs in tobacco encode beta-cyano-Lalanine hydratase/nitrilase. J. Biol. Chem. 276, 2616-2621.

Radin, J.W. 1983. Control of plant growth by nitrogen: Differences between cereals and broadleaf species. Plant Cell Environ. 6, 65-68.

Samiotakis, M., Ebbs, S.D. 2004. Possible evidence for transport of an iron cyanide complex by plants. Environ. Pollut. 127, 169-173.

Samuelson, M.E., Öhlén, E., Lind, M., Larsson, C.M. 1995. Nitrate regulation of nitrate uptake and nitrate reductase expression in barley grown at different nitrate:ammonium ratios at constant relative nitrogen addition rate. Physiol. Plant. 94, 254-260.
Seigler, D.S. 1991. Cyanide and cyanogenic glycosides, In: Rosenthal, G.A., Berenbaum, M.R. (Eds.), Herbivores: Their Interactions with Secondary Plant Metabolites, 2nd ed. Academic Press, San Diego, CA, pp 35-77.

Shearer, G., Kohl, D.H. 1993. Natural abundance of $15 \mathrm{~N}$ : Fractional contribution of two sources to a common sink and use of isotope discrimination., In: Knowles, C.J., Kohl, D.H. (Eds.), Nitrogen Isotope Techniques. Academic Press, San Diego, CA, pp 89-126.

Solomonson, L.P. 1981. Cyanide as a metabolic inhibitor, In: Vennesland, B., Conn, E.E., Knowles, C.J., Westley, J., Wissing, F. (Eds.), Cyanide in Biology. Academic Press, London, pp 11-28.

Widmer, T.L., Abawi, G.S. 2002. Relationship between levels of cyanide in Sudangrass hybrids incorporated into soil and suppression of Meloidogyne hapla. J. Nematol. 34, 16-22.

Wurtele, E.S., Nikolau, B.J., Conn, E.E. 1984. Tissue distribution of b-cyanoalanine synthase in leaves. Plant Physiol. 75, 979-982.

Yu, X.Z., Gu, J.D., Li, T.P. 2008. Availability of ferrocyanide and ferricyanide complexes as a nitrogen source to cyanogenic plants. Arch. Environ. Contam. Toxicol. 55, 229-237.

Yu, X.Z., Shen, P.P., Gu, J.G., Zhou, Y., Zhang, F.Z. 2012. Evidence of iron cyanides as supplementary nitrogen source to rice seedlings. Ecotoxicology. 21, 1642-1650.

Yu, X.Z., Trapp, S., Zhou, P., Wang, C., Zhou, X. 2004. Metabolism of cyanide by Chinese vegetation. Chemosphere. 56, 121-126.

Yu, X.Z., Zhang, F.Z. 2012. Activities of nitrate reductase and glutamine synthetase in rice seedlings during cyanide metabolism. J. Haz. Mat. 225-226, 190-194. 